\title{
Evaluation of Parenchymal Thyroid Diseases Using Ultrasonography
}

\author{
BS Naveen ${ }^{\circledR}$ \\ Assistant Professor, Department of Radiology, Akash Institute of Medical Science and Research Centre, Prasanna Road, Devanahalli, Bangalore, India.
}

\section{Abstract}

Background: Thyroid diseases are among the most common endocrine disorders seen in all age groups. The present study was conducted to determine parenchymal thyroid diseases using Ultrasonography (USG) in adult patients. Subjects and Methods: This study was conducted on 140 adult patients. Patients were divided into five groups such as Group I (normal); Group II had first detected, early untreated Hashimoto disease (EH); Group III comprised of chronic Hashimoto patients that are under treatment and/or follow up (H); Group IV had multinodular parenchymal hyperplasia (M); and Group V had nodular hyperplasia with Hashimoto (HM). They underwent spectral Doppler ultrasound and acoustic radiation force impulse using Siemens ACUSON S2000 machine. Results: The mean RI in group I was 0.54, in group II was 0.56, in group III was 0.42 , in group IV was 0.48 and in group V was 0.49 , mean AT in group I was 26.2 , in group II was 25.3 , in group III was 71.3 , in group IV was 46.2 and in group V was 45.1, mean SWV in group I was 1.54, in group II was 1.72, in group III was 1.20 , in group IV was 1.46 and in group V was 1.65. The difference was significant $(\mathrm{P}<0.05)$. Conclusion: Authors found that resistivity index, acceleration time and shear wave velocity together are reliable for differential diagnosis of parenchymal thyroid diseases.

Keywords: Thyroid diseases, Resistivity index, shear wave velocity, USG.

Corresponding Author: BS Naveen, Assistant Professor, Department of Radiology, Akash Institute of Medical Science and Research Centre, Prasanna Road, Devanahalli, Bangalore, India.

E-mail: hkps0320@gmail.com

Received: 06 February 2020

Revised: 11 March 2020

Accepted: 21 March 2020

Published: 29 April 2020

\section{Introduction}

Thyroid diseases are among the most common endocrine disorders seen in all age groups. They have great impact patients' health. ${ }^{[1]}$ Most of diseases are benign and often necessitate lifelong treatment and monitoring. ${ }^{[2]}$ Hyperthyroidism, hypothyroidism, subclinical hypothyroidism, congenital hypothyroidism, graves' disease, thyrotoxic nodule, thyroiditis, hashimoto's thyroiditis and thyroid cancer etc. are commonly occurring thyroid diseases. The common symptoms are nervousness, weight loss, dyspnea, palpitation, increased sweating, fatigue, tachycardia, eye complaints, weakness, increased appetite, vomiting, swelling of legs, chest pain etc. ${ }^{[3]}$

Ultrasonography (USG) is routinely performed procedure in patients with thyroid diseases. It is considered potent diagnostic tool. It is safe, cheap, time saving and has high sensitivity and specificity for thyroid lesion characterization. It can characterize most of thyroid lesions and detect small sized nodules less than $3 \mathrm{~mm} \cdot{ }^{[4]}$ Chronic autoimmune disease can present different radiologic characteristics based on its stage: for early stage disease (Early Hashimoto, EH) ultrasonography is performed at the beginning, and for chronic stage disease (Chronic Hashimoto, $\mathrm{CH}$ ) ultrasonography is done when the patient is under a medical treatment. Thus conventional ultrasound may not be able to differentiate thyroid diseases at different pathologic stages. In such cases, quantitative spectral doppler parameters, resistivity index (RI), acceleration time (AT), and quantitative elastography such as shear wave velocity (SWV) may be helpful. ${ }^{[5]}$ Considering this, the present study was conducted to determine parenchymal thyroid diseases using Ultrasonography (USG) in adult patients.

\section{Subjects and Methods}

This study was conducted in the department of Radiodiagnosis. It comprised of 140 adult patients age ranged 20-68 years of both genders. The study was approved from institutional ethical committee. All patients were well informed regarding the study and their consent was obtained.

Particulars such as name, age, gender was recorded in case history performa. A thorough clinical examination was performed in all patients. Patients were divided into 


\begin{tabular}{|llllll|}
\hline \multicolumn{7}{|c|}{ Table 1: Distribution of patients } \\
\hline Groups & Group & $\begin{array}{l}\text { Group } \\
\text { I }\end{array}$ & $\begin{array}{l}\text { Group } \\
\text { III }\end{array}$ & $\begin{array}{l}\text { Group } \\
\text { IV }\end{array}$ & $\begin{array}{l}\text { Group } \\
\text { V }\end{array}$ \\
$\begin{array}{llllll}\text { Dis- } \\
\text { eases }\end{array}$ & $\begin{array}{l}\text { Nor- } \\
\text { mal }\end{array}$ & EH & H & M & HM \\
$\begin{array}{l}\text { Num- } \\
\text { ber }\end{array}$ & 28 & 28 & 28 & 28 & 28 \\
\hline
\end{tabular}

Table 2: Assessment of spectraldoppler parameters

\begin{tabular}{|c|c|c|c|c|c|c|}
\hline $\begin{array}{l}\text { Param- } \\
\text { eters }\end{array}$ & $\begin{array}{l}\text { Grour } \\
\text { I }\end{array}$ & $\begin{array}{l}\text { Group } \\
\text { II }\end{array}$ & $\begin{array}{l}\text { Group } \\
\text { III }\end{array}$ & $\begin{array}{l}\text { Group } \\
\text { IV }\end{array}$ & $\begin{array}{l}\text { Group } \\
\text { V }\end{array}$ & $\begin{array}{l}P \\
\text { value }\end{array}$ \\
\hline RI & 0.54 & 0.56 & 0.42 & 0.48 & 0.49 & 0.02 \\
\hline AT & 26.2 & 25.3 & 71.3 & 46.2 & 45.1 & 0.001 \\
\hline SWV & 1.54 & 1.72 & 1.20 & 1.46 & 1.65 & 0.01 \\
\hline
\end{tabular}

five groups such as group I (normal); group II had first detected, early untreated Hashimoto disease (EH); group III comprised of chronic Hashimoto patients that are under treatment and/or follow up (H); group IV had multinodular parenchymal hyperplasia (M); and group $\mathrm{V}$ had nodular hyperplasia with Hashimoto (HM). They underwent spectral Doppler ultrasound and acoustic radiation force impulse using Siemens ACUSON S2000 machine. Quantitative spectral doppler parameters such as resistivity index (RI), acceleration time (AT) and quantitative elastography such as shear wave velocity (SWV) was recorded. Results were subjected to statistical analysis for correct inference. P value less than 0.05 was considered significant.

\section{Results}

[Table 1] shows distribution of patients based on diseases and each group had 28 patients.

[Table 2, Figure 1] shows that mean RI in group I was 0.54, in group II was 0.56 , in group III was 0.42 , in group IV was 0.48 and in group V was 0.49 , mean AT in group I was 26.2, in group II was 25.3, in group III was 71.3, in group IV was 46.2 and in group V was 45.1, mean SWV in group I was 1.54, in group II was 1.72, in group III was 1.20, in group IV was 1.46 and in group $\mathrm{V}$ was 1.65 . The difference was significant $(\mathrm{P}<0.05)$.

\section{Discussion}

The application of color and power doppler modes has huge benefit to determine thyroid gland vascularity. This can evaluate the disease progression, specifically with Graves ' disease and thyroiditis. Moreover it is also capable of assessing vascularity within septations in thyroid cystic lesions which

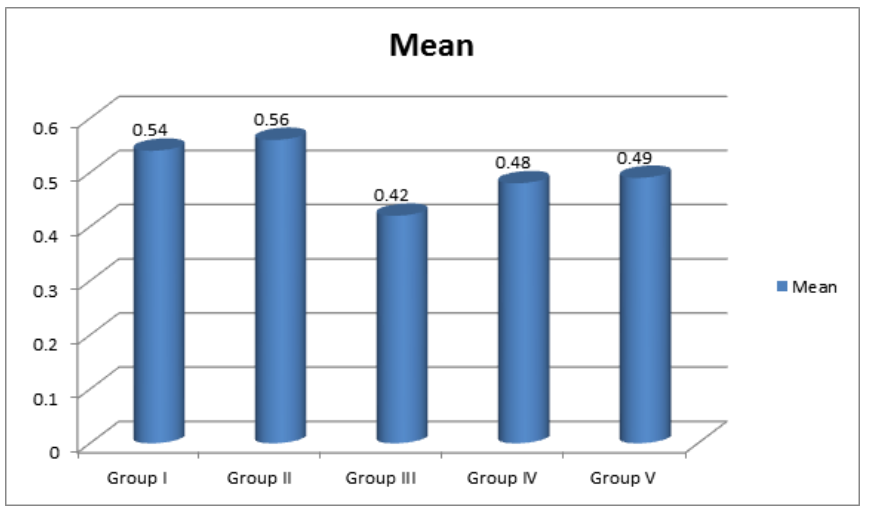

\section{Figure 1: RI in different groups}

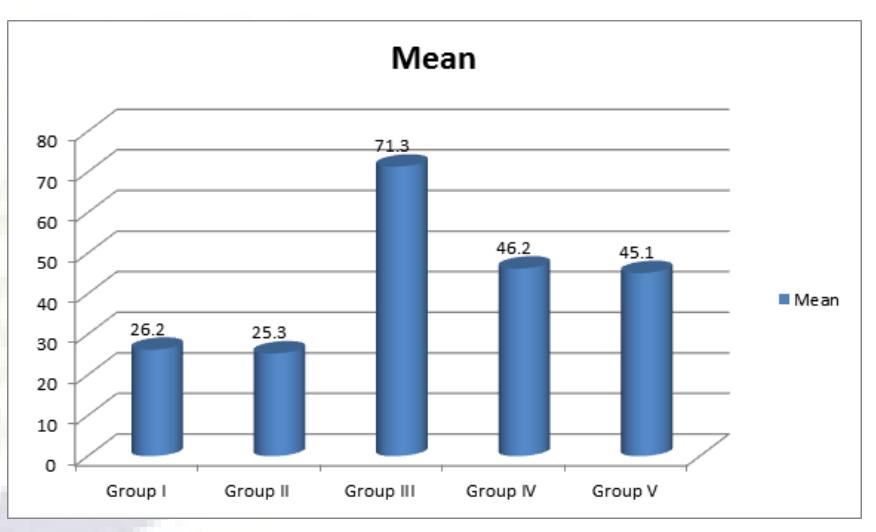

\section{Figure 2: Assessment of AT in groups}

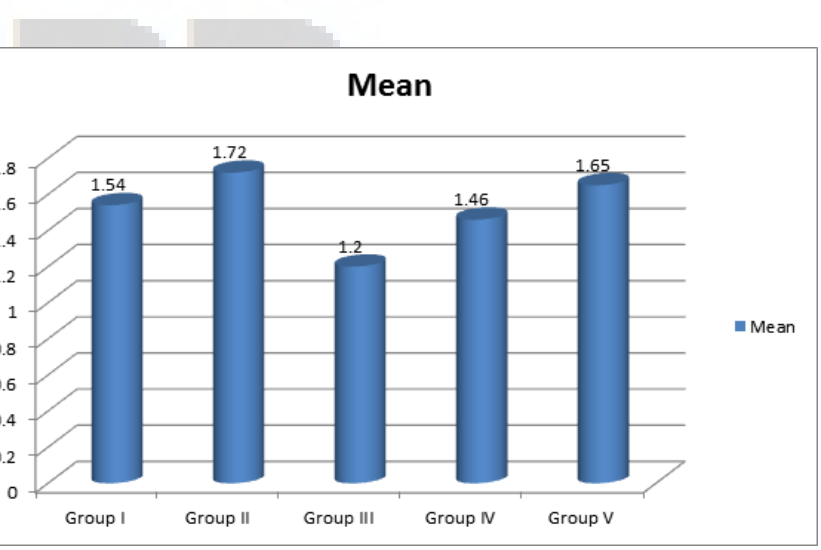

Figure 3: Assessment of SWV in different groups

differentiates benign and malignant cysts. ${ }^{[6]}$ USG is better for post-operative follow up and for FNA and True cut needle biopsy guidance. However, it is still considered to be operator dependant, poorly identify the retrosternal and laryngeal extension and lack of sensitivity and specificity for 
some cases. ${ }^{[7]}$

Thyroid USG is used for the measurement of parenchymal volume, assessing vascular characteristic of gland, screening, and differentiation of the nodules. ${ }^{[8]}$ After the technologic developments about the transducers and high resolution screens, gray scale and Doppler examinations became easier. ${ }^{[9]}$ Additionally, SWV expensed the scope of elastography and enabled the quantitative examination of the nodules and the thyroid parenchyma with the help of hardware and software. Besides thyroid nodule evaluations, many works reported value of elastography to detect changes of thyroid parenchyma in diseases that affects thyroid parenchyma including HT. ${ }^{[10]}$ The present study was conducted to determine parenchymal thyroid diseases using Ultrasonography (USG) in adult patients.In present study, we included 140 adult patients. Patients were divided into five groups such as group I (normal); group II had first detected, early untreated Hashimoto disease (EH); group III comprised of chronic Hashimoto patients that are under treatment and/or follow up (H); group IV had multinodular parenchymal hyperplasia $(\mathrm{M})$; and group $\mathrm{V}$ had nodular hyperplasia with Hashimoto (HM). Yildirim et al, ${ }^{[1]}$ in their study evaluated findings of 227 patients ( 179 females, 48 males) that underwent spectral Doppler ultrasound and acoustic radiation force impulse. Authors found no significant effect of gender or volume on the differentiation of disease pattern. RI $(0.41 \pm$ $0.06)$ and $\mathrm{SWV}$ values $(1.19 \pm 0.18 \mathrm{~m} / \mathrm{s})$ were the lowest. AT values $(>55 \mathrm{~ms})$ were the highest in EH group. Existence of $\mathrm{H}$ decreased RI and SWV values, while it extended AT in a different thyroid disease.

We found that mean RI in group I was 0.54 , in group II was 0.56 , in group III was 0.42 , in group IV was 0.48 and in group $\mathrm{V}$ was 0.49 , mean AT in group I was 26.2, in group II was 25.3, in group III was 71.3, in group IV was 46.2 and in group $\mathrm{V}$ was 45.1 , mean SWV in group I was 1.54 , in group II was 1.72 , in group III was 1.20, in group IV was 1.46 and in group V was 1.65. Popoveniuc $\mathrm{G}$, et al, ${ }^{[12]}$ in their study assessed of thyroid diseases by ultrasound in 167 patients. The study groups were classified into 9 groups. Authors found that thyroid USG has great role in assessment of thyroid disease and in their follow up.

The limitation of the study is small sample size. Only one radiologist examined all the images. There can be radiologist specific errors.

\section{Conclusion}

Authors found that resistivity index, acceleration time and shear wave velocity together are reliable for differential diagnosis of parenchymal thyroid diseases.

\section{References}

1. Surks MI, Chopre IJ, Mariash CN, Nicoloff JT, Solomon DH. American Thyroid Association guidelines for use of laboratory tests in thyroid disorders. JAMA. 1990;263(11):1529-1561.

2. Bagchi N, Brown TR, Parish RF. Thyroid dysfunction in adults over age 55 years. Arch Intern Med. 1990;150(4):785787. Available from: https://dx.doi.org/doi:10.1001/archinte. 1990.00390160053012 .

3. Sarkis LM, Norlen O, Aniss A, Watson N, Delbridge LW, Sidhu SB, et al. The Australian experience with the Bethesda classification system for thyroid fine needle aspiration biopsies. Pathology. 2014;46(7):592-595. Available from: https://dx. doi.org/10.1097/pat.0000000000000168.

4. Ma BY, Parajuly SS, Ying SX, Lan PY. Application of shear wave elastography in fine needle aspiration biopsy for thyroid nodule. J Pak Med Assoc. 2014;64(8):954-961.

5. Liu BX, Xie XY, Liang JY, Zheng YL, Huang GL, Zhou LY, et al. Shear wave elastography versus real time elastography on evaluation thyroid nodules: A preliminary study. Eur J Radiol. 2014;83(7):1135-1178. Available from: https://doi. org/10.1016/j.ejrad.2014.02.024.

6. Woliński K, Szczepanek-Parulska E, Stangierski A, Gurgul E, Rewaj-Łosyk M, Ruchała M. How to select nodules for fine needle aspiration biopsy in multinodular goitre. Role of conventional ultrasonography and shear wave elastography A preliminary study. Endokrynol Pol. 2014;65(2):114-118. Available from: https://doi.org/10.5603/ep.2014.0016.

7. Jung WS, Kim JA, Son EJ, Youk JH, Park CS. Shear wave elastography in evaluation of cervical lymph node metastasis of papillary thyroid carcinoma: Elasticity index as a prognostic implication. Ann Surg Oncol. 2015;22(1):111-116. Available from: https://doi.org/10.1245/s10434-014-3627-4.

8. Szczepanek-Parulska E, Woliński K, Stangierski A, Gurgul E, Biczysko M, Majewski P. Comparison of Diagnostic Value of Conventional Ultrasonography and Shear Wave Elastography in the Prediction of Thyroid Lesions Malignancy. PLoS One. 2013;8(11):e81532. Available from: https://dx.doi.org/ 10.1371/journal.pone.0081532.

9. Colakoglu B, Yildirim D, Alis D, Ucar G, Samanci C, Ustabasioglu FE, et al. Elastography in Distinguishing Benign from Malignant Thyroid Nodules. J Clin Imaging Sci. 2016;6:51-56. Available from: https://dx.doi.org/10.4103/ 2156-7514.197074.

10. Calvete AC, Mestre JDB, Gonzalez JMR, Martinez ES, Sala BT, Zambudio AR. Acoustic Radiation Force Impulse Imaging for Evaluation of the Thyroid Gland. J Ultrasound Med. 2014;33(6):1031-1040. Available from: https://dx.doi.org/10. 7863/ultra.33.6.1031.

11. Yildirim D, Alis D, Bakir A, Ustabasioglu F, Samanci C, Colakoglu B. Evaluation of parenchymal thyroid diseases with multiparametric ultrasonography. Indian J Radiol Imaging. 2017;27(4):463-463. Available from: https://dx.doi.org/10. 4103/ijri.ijri_409_16.

12. Popoveniuc G, Jonklaas J. Thyroid Nodules. Med Clin North Am. 2015;96(2):329-349. Available from: https://dx.doi.org/ 10.1016/j.mcna.2012.02.002. 
Copyright: (C) the author(s), 2020. It is an open-access article distributed under the terms of the Creative Commons Attribution License (CC BY 4.0), which permits authors to retain ownership of the copyright for their content, and allow anyone to download, reuse, reprint, modify, distribute and/or copy the content as long as the original authors and source are cited.

How to cite this article: Naveen BS. Evaluation of Parenchymal Thyroid Diseases Using Ultrasonography. Asian J. Med. Radiol. Res. 2020;8(1):32-35.

DOI: dx.doi.org/10.47009/ajmrr.2020.8.1.6

Source of Support: Nil, Conflict of Interest: None declared. 